\title{
Investigation of the levels of oxidative stress parameters in HIV and HIV-TB co-infected patients
}

\author{
Olufunsho Awodele ${ }^{1}$, Sunday O. Olayemi ${ }^{1}$, Joseph A. Nwite ${ }^{1}$, Titilope A. Adeyemo ${ }^{2}$ \\ ${ }^{1}$ Department of Pharmacology, College of Medicine, University of Lagos, Lagos, Nigeria \\ ${ }^{2}$ Department of Haematology and Blood Transfusion, Faculty of Clinical Sciences, College of Medicine, University \\ of Lagos, Lagos, Nigeria
}

\begin{abstract}
Introduction: Among opportunistic pathogens associated with acquired immunodeficiency syndrome (AIDS), Mycobacterium tuberculosis is distinguished by its relative virulence and potential for person-to-person transmission. Oxidative stress is associated with TB infection with a high level in patients with HIV-TB co-infection. However, the comparative level of oxidative stress in HIV patients on highly active antiretroviral therapy (HAART) and naïve (untreated) HIV patients is not clear.

Methodology: This study is aimed to determine the level of oxidative stress and haematological parameters in HIV patients (naïve), HIV patients undergoing HAART, and HIV-TB co-infected patients. In total, 100 consenting subjects were recruited from the AIDS Prevention Iniative in Nigeria (APIN) Clinic. For controls, normal male healthy volunteers were recruited from the blood donor clinic and females from the APIN clinic staff members, both of the Lagos University Teaching Hospital. Measurements of antioxidant enzyme activity and lipid peroxidation were performed according to standard procedures. Haematological parameters were determined using a fully automated hematology analyzer.

Results: Red blood cells significantly decreased $(\mathrm{P} \leq 0.001)$ in all patients when compared with control subjects. The lipid peroxidation (MDA) was significantly high $(\mathrm{P} \leq 0.05)$ in naive patients when compared to HIV patients on HAART. The decrease in the levels of GSH in both naive and HIV-TB co-infected patients $(\mathrm{P} \leq 0.001)$ and HIV patients on HAART $(\mathrm{P}<0.05)$ were significant when compared to control patients.

Conclusion: There is lower antioxidant level and higher MDA in naive and HIV-TB co-infected patients as compared to HIV patients on HAART and the seronegative patients.
\end{abstract}

Key words: HIV untreated; HIV treated; HAART; HIV-TB co-infection; oxidative stress; haematological parameters

J Infect Dev Ctries 2012; 6(1):79-85.

(Received 04 February 2011 - Accepted 12 March 2011)

Copyright $(2012$ Awodele et al. This is an open-access article distributed under the Creative Commons Attribution License, which permits unrestricted use, distribution, and reproduction in any medium, provided the original work is properly cited

\section{Introduction}

Acquired immunodeficiency syndrome (AIDS) is a fatal illness caused by a retrovirus known as the human immunodeficiency virus (HIV) that breaks down the body's immune system, infects $\mathrm{CD} 4^{+}$cells initially, and progressively leads to AIDS [1]. Among the opportunistic pathogens associated with AIDS, Mycobacterium tuberculosis is distinguished by its relative virulence and potential for person-to-person transmission [2,3]. Persons infected with HIV are particularly susceptible to tuberculosis, both from the reactivation of latent infection and from new infection with rapid progression to active disease $[2,3]$.

In 2008, more than one-third of HIV-infected individuals were also infected with tuberculosis (TB) bacteria [4]. In 2007, of the 9.3 million new TB cases, 1.4 million were also living with HIV. In many parts of the world TB is a leading killer of HIVinfected individuals and 500,000 HIV positive TB patients died in 2007 [5,6]. It is widely reported that oxidative stress, an imbalance between production and elimination of chemically reactive species, such as reactive oxygen species (ROS) [7], is involved in HIV infection [8]. Viral Tat protein induces an enhanced ROS production in HIV-infected patients by mitochondrial generation of superoxide anion [9], which in turn may activate nuclear factor $\kappa \mathrm{B}(\mathrm{NF}-\kappa \mathrm{B})$ [8], thus increasing HIV transcription. Oxidative stress also has been shown to be associated with TB infection through activation of phagocytes by mycobacteria which may further contribute to immunosuppression [10,11]. Furthermore, an earlier report [12] has shown high levels of oxidative stress 
in HIV-TB co-infected patients. A variety of enzymatic (superoxide dismutase, catalase, glutathione peroxidase, etc.) and nonenzymatic (ascorbate, etc.) antioxidants present in human serum become insufficient to circumvent HIV-1 replication secondary to cellular ROS production (superoxide anion, hydroxyl radical, hydrogen peroxide etc.) by a pro-oxidant effect of inflammatory cytokines and/or a polymorphonuclear leukocyte activation [13].

Friis-Moller et al. [14] have shown that HIVinfected patients are in oxidative imbalance early in the disease; serum and tissue anti-oxidants levels are low and peroxidation products elevated. High plasma levels of malondialdehyde (MDA), reduced plasma glutathione (GSH), and decreased superoxide dismutase (SODs) activities are normally found. HIV and TB infection also result in considerably reduced vitamin $\mathrm{C}$ concentrations [15]. Formation of free radicals from mitochondrial leakage due to increased oxygen consumption, inflammatory and reperfusion processes, and leukocyte activation elevate oxidative stress in erythrocytes [16].

The pathogenesis of immunodeficiency during chronic HIV infection includes apoptosis of CD4 T cells that is influenced by ROS production [17]. Valcour and Shiramizu [18] have in their work indicated that an increased level of ROS may also increase blood-brain barrier permeability and contribute to HIV-associated dementia. Access to potent antiretroviral therapy (ART) decreases morbidity and mortality due to HIV infection and AIDS [19] and has made HIV infection a manageable chronic illness. Unfortunately, many patients who are prescribed chronic ART experience drug toxicities that include metabolic, hepatic, neurological and cardiovascular complications [20].

Highly active anti-retroviral therapy (HAART) may increase chemically reactive species in circulation, possibly by producing more oxidized metabolites deriving from the interaction between ROS and infected-cell biomolecules [21-23]. This is supported by several biochemical mechanisms, such as mitochondrial interference, following treatment with HAART-NRTI (nucleoside reverse transcriptase inhibitors) [22], and activation of the $\mathrm{P}_{450}$ hepatic system by HAART, which are protease inhibitors (PI) [21]. A putative mechanism of these toxicities includes inhibition of mitochondrial DNA polymerase- $\gamma$, with resultant mitochondrial DNA depletion and tissue-specific mitochondrial dysfunction [24]. Other metabolic toxicities such as dyslipidemia and insulin resistance appear to be predominately associated with protease inhibitor (PI) exposure, likely through effects on lipid metabolism and cellular glucose uptake, respectively. [20]. Although specific mechanisms of ART-associated toxicities are largely unknown, Day and Lewis [15] showed that all of these processes may be mediated at a fundamental level by free radical-induced cellular damage, also referred to as oxidant stress. Montine et al. [25] and Shishehbor et al. [26] independently described oxidant stress as an underlying pathogenic mechanism during various human disease conditions including cardiovascular and neurodegenerative diseases.

In view of the aboveconsiderations, this study aimed to determine the oxidative stress and haematological parameters in HIV patients (naïve, who have not started HAART treatment), HIV patients undergoing HAART treatment, and HIV-TB co-infected patients. The findings obtained from this study will further enhance our understanding of the level of oxidative stress in HIV patients who have not been treated and the effect of HAART on oxidative stress in HIV patients undergoing treatment.

\section{Methodology}

Study site

The study was conducted at the AIDS Prevention Iniative in Nigeria (APIN) Clinic in Lagos University Teaching Hospital, Lagos, Nigeria, which is one of the treatment centers for the HIV relief program in Nigeria. The clinic runs from 8:00 a.m. to 4:00 p.m. (Monday to Friday) and has about 10,000 registered patients.

\section{Subjects}

A total of 100 consenting subjects (45 males, 55 females), aged 18 to 40 years were involved in this study. The subjects were comprised of normal human volunteers (NHV, $\mathrm{n}=25)$, HIV naïve patients $(\mathrm{n}=$ $25)$, HIV patients on HAART treatment $(n=25)$ and HIV-TB co-infected patients on treatment with HAART and anti-tuberculous therapy (ATT), (HIV/TB, $n=25)$. The patients were recruited from the AIDS Prevention Iniative in Nigeria (APIN) Clinic. The normal human healthy volunteers (males) were recruited from the blood donor clinic and (females) from the APIN clinic staff members, both of the Lagos University Teaching Hospital (LUTH), Lagos, Nigeria. 


\section{Ethical appoval and patient consent}

Ethical approval was obtained from the Research and Ethics Committee of Lagos University Teaching Hospital, (LUTH), Lagos, Nigeria. Patient consent was obtained and the details of the study explained to each individual subject before sample collection was done.

\section{Eligibility}

Patients with complications such as renal, endocrine or hepatic diseases, diabetes mellitus, obesity, viral and/or bacterial infections were excluded from the study. An age bracket of between 18 and 40 years was employed to avoid having resultsaffected by factors of old age which has also been shown to be associated with oxidative stress.

\section{Blood samples}

From each volunteer, $10 \mathrm{ml}$ of venous blood was collected as follows: $5 \mathrm{ml}$ in Na-EDTA for full blood count and $5 \mathrm{ml}$ in a heparinized vacutainer for the oxidative stress parameters. Plasma was extracted by centrifuging the heparinized whole blood in a Whisperfuge centrifuge Model 684 (GEA Westfalia, Northvale, NJ, USA) at 2500 revolutions for 10 minutes and used for the analysis of malondiadehyde (MDA), vitamin $\mathrm{C}$, reduced glutathione (GSH), superoxide dimutase (SOD), and catalase. The plasma for enzyme analysis was stored at $-83^{\circ} \mathrm{C}$ before the analysis was done.

\section{Measurement of haematological parameters,} antioxidant enzymes and lipid peroxidation

The red blood cell count (RBC), total white blood cell count (WBC), platelet count, total hemoglobin and hematocrit were determined using an automated haematology analyzer (Pentra-XL 80, Horiba ABX, Kyoto, Japan). The CD4+ lymphocyte count was estimated by a Fluorescence Activated Cell Sorter (FACS) count system (Becton Dickinson, Franklin Lakes, NJ, USA).

Measurements of antioxidant enzyme activity and lipid peroxidation were performed according to standard procedures: catalase [27-29]; superoxide dismutase (SOD) [29]; malondialdehyde (MDA) [29, 30]; reduced glutathione (GSH) and Glutathione- $S$ transferase (GST) were determined using the methods of Beers and Seizer [27] and Beuge and Aust [28].

\section{Statistical analysis}

The results are presented as mean \pm standard error of the mean (SEM). Statistical significance between the groups was analyzed by means of the student t-test and Tukey's multiple comparison test. $P$ values less than 0.05 were considered significant.

\section{Results}

Standard treatment guidelines were used to place all the categories of patients on the appropriate therapeutic regimen. The HIV patients on HAART treatment were placed on either a combination of two nucleoside reverse transcriptase inhibitors (zidovudine, lamivudine, tenofovir) and one non nucleoside reverse transcriptase inhibitor (nevirapine and efavirenz) or two nucleoside reverse transcriptase inhibitors (zidovudine, lamivudine, tenofovir) and two protease inhibitors (lopinavir and ritonavir). The HIV-TB co-infected patients were placed on a fixed dose of combined (FDC) antituberculous agents (rifampicin, isoniazid, parazinamide, ethambutor) together with the HAART treatment. However, nevirapine and lopinavir were avoided from the therapy of this category of patients because of its established drug-drug interaction and adverse effects.

Table 1 shows the demographics of the study group as follows: the mean age (in years) of normal human volunters was $28.60 \pm 6.11$, of HIV-infected patients not on HAART $33.48 \pm 3.11$, of HIVinfected patients on HAART $35.52 \pm 4.11$ and of HIV-TB co-infected patients on treatment $32.84 \pm$ 6.12. The sex distribution (male:female) was 40:60 in NHV and naïve patients, 56:44 in HIV patients on HAART, and 48:52 in HIV-TB co-infected patients.

Table 2 shows that the levels of $\mathrm{CD} 4^{+}$cell count and total RBC count were significantly decreased (P $\leq 0.001)$ in all categories of patients when compared with control subjects. There was also a significant decrease $(\mathrm{P} \leq 0.05)$ in haemoglobin and haematocrit of the HIV-TB co-infected patients when compared with the control group. The results also show a significant $(\mathrm{P}<0.05)$ reduction in the white blood cell counts between the HIV (HAART) and naive patients. The platelets results show a significant $(\mathrm{P} \leq$ $0.05)$ increase between HIV-TB co-infected patients and naïve and control patients.

The levels of plasma protein were significantly $(\mathrm{P}$ $\leq 0.001)$ increased in naive and HIV-TB co-infected patients compared to the NHV subjects (Table 3). Protein results also showed a significant $(\mathrm{P} \leq 0.01)$ decrease among the HIV (HAART), HIV-TB coinfected, and naive patients. The lipid peroxidation (MDA) was significantly high $(\mathrm{P} \leq 0.05)$ in naive patients when compared to those of HIV-infected patients on HAART and control subjects. The 
Table 1. Demographic Characteristics of studied subjects

\begin{tabular}{|l|c|c|c|c|}
\hline Parameters & NHV & Naive & HIV (HAART) & HIV-TB co-infection \\
\hline No of Subjects & 25 & 25 & 25 & 25 \\
\hline Sex (M:F)\% & $40: 60$ & $40: 60$ & $56: 44$ & $48: 52$ \\
\hline Age (Mean \pm SD)yrs & $28.60 \pm 6.11$ & $33.48 \pm 3.11$ & $35.52 \pm 4.11$ & $32.84 \pm 6.12$ \\
\hline
\end{tabular}

NHV( Normal Human Volunteers), Naive(HIV patients not on HAART), HIV (HIV patients on HAART), HIV-TB co-infection on treatment

Table 2. Haematological parameters of HIV and HIV-TB patients

\begin{tabular}{|l|c|l|l|l|}
\hline Parameters & \multicolumn{1}{|c|}{ NHV } & \multicolumn{1}{c|}{ Naive } & HIV (HAART) & HIV-TB co-infection \\
\hline RBC $\left(10^{6} / \mu \mathrm{l}\right)$ & $4.88 \pm 0.24$ & $4.03 \pm 0.11^{* * *}$ & $3.76 \pm 0.12^{* * *}$ & $3.76 \pm 0.06^{* * *}$ \\
\hline WBC $\left(10^{6} / \mu \mathrm{l}\right)$ & $5.51 \pm 0.25$ & $6.78 \pm 0.45$ & $4.68 \pm 0.30^{\alpha}$ & $5.72 \pm 0.46$ \\
\hline CD4+count $(\mathrm{cell} / \mu \mathrm{l})$ & $775.20 \pm 28.06$ & $157.36 \pm$ & $300.90 \pm$ & $300.80 \pm 31.10^{* * * \alpha}$ \\
& & $48.49^{* * *}$ & $38.36^{* * * \alpha}$ & \\
\hline Haemoglobin $(\mathrm{g} / \mathrm{dl})$ & $12.80 \pm 0.54$ & $11.13 \pm 0.40$ & $11.58 \pm 0.64$ & $11.04 \pm 0.37^{*}$ \\
\hline Haematocrit $\%$ & $38.74 \pm 1.56$ & $34.43 \pm 1.17$ & $36.57 \pm 1.80$ & $33.52 \pm 1.11^{*}$ \\
\hline Platelets $\left(10^{3} / \mu \mathrm{l}\right)$ & $220.70 \pm 19.08$ & $219.50 \pm 17.86$ & $244.20 \pm 15.78$ & $297.70 \pm 19.12^{\alpha *}$ \\
\hline
\end{tabular}

${ }^{*} \mathrm{P} \leq 0.05, * * \mathrm{P} \leq 0.01,{ }^{* * *} \mathrm{P} \leq 0.001$ all in comparison with the $\mathrm{NHV}$

${ }^{\alpha} \mathrm{P} \leq 0.05$ in comparison with Naive

Table 3. Lipid peroxidation and anti oxidants parameters in HIV and HIV-TBpatients

\begin{tabular}{|l|c|c|c|c|}
\hline Parameters & NHV & Naive & HIV (HAART) & HIV-TB co-infection \\
\hline Proteins $(\mathrm{mg} / \mathrm{ml})$ & $35.53 \pm 0.83$ & $54.29 \pm 1.35^{* * *}$ & $37.25 \pm 1.83^{\alpha}$ & $47.13 \pm 1.48^{* * *} \alpha+$ \\
\hline MDA $(\mathrm{nmol} / \mathrm{ml})$ & $2.063 \pm 0.67$ & $4.403 \pm 0.55^{*}$ & $2.325 \pm 0.32^{\alpha}$ & $3.113 \pm 0.67^{\beta}$ \\
\hline GSH $(\mathrm{mg} / \mathrm{dl})$ & $51.41 \pm 6.63$ & $26.83 \pm 2.23^{* * *}$ & $33.62 \pm 3.60^{*}$ & $25.45 \pm 3.33^{* * *}$ \\
\hline SOD $(\mathrm{Iu} / \mathrm{ml})$ & $5.002 \pm 1.95$ & $2.137 \pm 0.63$ & $3.364 \pm 0.82$ & $2.057 \pm 0.67$ \\
\hline CAT $(\mathrm{Iu} / \mathrm{ml})$ & $43.10 \pm 6.99$ & $17.55 \pm 4.50^{* *}$ & $31.01 \pm 6.12$ & $20.37 \pm 5.28^{* *}$ \\
\hline Vitamin C $(\mathrm{mg} / \mathrm{dl})$ & $0.567 \pm 0.03$ & $0.161 \pm 0.04$ & $0.280 \pm 0.02^{\alpha}$ & $0.114 \pm 0.03^{+}$ \\
\hline
\end{tabular}

MDA, malondialdehyde; GSH, reduced glutathione ; GST, SOD, superoxide dismutase; CAT, catalase $* \mathrm{P} \leq 0.05, * * \mathrm{P} \leq 0.01, * * * \mathrm{P} \leq 0.001$ all in comparison with the NHV ${ }^{a} \mathrm{P} \leq 0.01$ comparison with Naive ${ }^{+} \mathrm{P} \leq 0.01$ comparison with HIV (HAART) $\quad{ }^{\beta} \mathrm{P} \leq 0.05$ comparison with HIV (HAART) 
decrease in the levels of GSH in both naive and HIVTB co-infected patients $(\mathrm{P} \leq 0.001)$ and HIV patients on HAART treatment group $(\mathrm{P}<0.05)$ was significant when compared to the levels of the control group. There was also a significant decrease in the levels of catalase of naive patients $(\mathrm{P} \leq 0.01)$ and HIV-TB co-infected patients $(\mathrm{P} \leq 0.05)$ when compared with those of the control group. The results on vitamin $\mathrm{C}$ showed a statistically significant $(\mathrm{P} \leq 0.01)$ increase between HIV (HAART) and naive patients; it further showed a statistically significant (P $\leq 0.01$ ) decrease in the levels between HIV-TB coinfected patients and HIV (HAART) patients.

\section{Discussion}

Much research has been conducted in the areas of HIV-TB co-infection, but there few studies in the literature report on oxidative stress markers comparing single infection to co-infection and also comparing the oxidative stress in HIV untreated patients with HIV patients on HAART. This present study was developed to generate data in these areas.

The level of plasma protein in HIV naïve patients was significantly high compared with the HIV patients on HAART. This observation may indicate the chronic inflammatory state of HIV naive patients which will definitely enhance their state of oxidative stress. Although there was a reduced level of plasma protein in HIV patients on HAART, antiretroviral therapy has also been known to increase chemically reactive species in circulation, possibly by producing more oxidized metabolites deriving from the interaction between ROS and infected-cell biomolecules as reported by Martín et al., [21], Hulgan et al., [22], and Lizette et al., [23]. This argument may be substantiated by the report of FriisMoller et al. [14], which showed that HIV-infected patients are in oxidative imbalance early in the disease; serum and tissue anti-oxidants levels are low and peroxidation products elevated. Furthermore, the high $(\mathrm{P} \leq 0.01)$ MDA plasma levels in the naive group could suggest that HIV is a faster generator of free radicals than drugs as evidenced in those untreated patients who are dependent on the body's immunity alone for defence against infections.

The high level $(\mathrm{P} \leq 0.05)$ of MDA in the HIV-TB co-infection compared with the HIV patients on HAART could be as a result of increased ROS in HIV and TB infections as previously reported in patients with HIV and TB [31-34]. This may further support a role for oxidative stress in the pathogenesis of HIV and TB patients and subsequently suggest a higher rate of viral multiplication and oxidative stress in naive patients as shown in this study. The correlation between high MDA concentrations and low concentrations of some anti-oxidants suggests increased utilisation by ROS as an important contributing factor to the lower concentrations of anti-oxidants [35]. HIV-infected individuals have been reported to show decreased antioxidant concentrations, disruption in glutathione metabolism, and enhanced spontaneous generation of ROS [3638]. Apart from the HIV-TB induced oxidative stress, malnutrition may also influence anti-oxidant status and oxidative stress in patients [39]. The present study corroborates the aforementioned as there was a significant decrease $(\mathrm{P} \leq 0.01)$ in the level of vitamin $\mathrm{C}$ in the naïve patients as compared with the HIV (HAART) patients. Hence, it appears that suitable exogenous anti-oxidant supplementation may protect these patients from free radical attack and thus be beneficial in their management.

Human monocyte-derived macrophages are involved in a variety of pathological events in HIV infection, the hallmark of which is immunodeficiency with progressive $\mathrm{CD} 4^{+} \mathrm{T}$ lymphocyte depletion. HIV infections cause a chronic inflammation as shown by high plasma levels of inflammatory cytokines and production of ROS in seropositive individuals. In the present study, there was a statistically significant $(\mathrm{P} \leq$ $0.001)$ decrease in the level of $\mathrm{CD}^{+}$counts in HIVTB co-infection, HIV patients under treatment, and the ART naive group when compared to the HIV seronegative normal human volunteers. There was also a decrease $(\mathrm{P} \leq 0.05)$ in the levels of the $\mathrm{CD} 4^{+}$ counts in the naïve patients compared with those of the HIV (HAART) and HIV-TB co-infected patients. This observation is an indication of the level of depletion of the host immune system that is often associated with HIV infection. Haematological abnormalities are among the most common complications of infection with HIV [40]. In this study, the red blood cells were significantly $(\mathrm{P} \leq$ 0.001 ) reduced by the HIV, HIV-TB infections as compared with the levels in the control patients.

\section{Conclusion}

The data obtained from this study are sufficient to conclude that there is lower antioxidant potential and higher lipid peroxidation in naive and HIV-TB co-infected patients as compared to the HIV patients on HAART and the seronegative patients. Thus the general understanding of drug-induced free radical generation may not be absolutely applicable to HIV 
management. It may be advisable to always incorporate exogenous antioxidants in the regimen of HIV and HIV-TB co-infected patients.

\section{Acknowledgements}

The authors thank the management and staff of the APIN clinic, Lagos University Teaching Hospital, who provided registration, laboratory investigations, and free treatment to all registered HIV patients involved in this study. The authors also thank the participants who volunteered their time for this study.

\section{References}

1. Scott MC, Walusimbi M, Johnson DF, Lancioni C, Charlebois E, Baseke J, Chervenak KA, Mugerwa RD, Havlir DV, Kizza H, Whalen CC, Boom WH (2010) Tuberculosis Treatment in HIV Infected Ugandans with CD4 Counts $>350$ Cells $/ \mathrm{mm}^{3}$ Reduces Immune Activation with No Effect on HIV Load or CD4 Count. PLoS One 5: e9138.

2. Daley CL, Small PM, Schecter GF, Schoolnik GK, McAdam RA, Jacobs WR (1992) An outbreak of tuberculosis with accelerated progression among persons infected with the human immunodeficiency virus. An analysis using restriction-fragment-length polymorphisms. N Engl J Med 326: 231-235.

3. Murcia-Aranguren MI, Gómez-Marin JE, Alvarado FS, Bustillo JG, Mendivelson E, Gómez B, León CI, Triana WA, Vargas EA, and Rodríguez E (2001) Frequency of tuberculous and non-tuberculous mycobacteria in HIV infected patients from Bogota, Colombia. BMC Infect Dis 1: 21.

4. World Health Organization (2009) "Global Tuberculosis Control: A Short Update To The 2009 Report". World Health Organization, Geneva, 2009. www.who.int/tb/publications/global_report/2002/index.html Last accessed 4 December 2012.

5. Chin J (2007) The AIDS Pandemic: the collision of epidemiology with political correctness. Oxford: Radcliffe Publishing, 248 p.

6. World Health Organization (2009) Tuberculosis Facts, www.who.int/tb/publications/2009/tbfactsheet2009onepage. pdf. Last accessed 18 November 2009.

7. Halliwell B ( 1994) Free radicals, antioxidants, and human disease: curiosity, cause, or consequence? The Lancet 344 : 721-724.

8. Schreck R, Rieber P, Baeuerle PA (1991) Reactive oxygen intermediates as apparently widely used messengers in the activation of the NF- $\kappa \mathrm{B}$ transcription factor and HIV-1, The EMBO Journal 10: 2247-2258.

9. Sacktorab N, Haugheya N, Cutlerc R, Tamarac A, Turchana J, Pardoa C, Vargasa D, Nath A (2004) Novel markers of oxidative stress in actively progressive HIV dementia. Journal of Neuroimmunology 157: 176-184.

10. Jack CI, Jackson MJ, Hind CR (1994) Circulating markers of free radical activity in patients with pulmonary tuberculosis. Tuber Lung Dis 75: 132-13.7.

11. Grimble RF (1994) Malnutrition and the immune response. Impact of nutrients on cytokine biology in infection. Trans $\mathrm{R}$ Soc Trop Med Hyg 88: 615-619.

12. Macallan DC ( 1999) Malnutrition in tubercclosis. Diag Microbiol Infect Dis 34: 153-157.
13. Perl A, Banki K (2000) Genetic and Metabolic Control of the Mitochondrial Transmembrane Potential and Reactive Oxygen Intermediate Production in HIV Disease. Antioxidants \& Redox Signaling 2: 551-573.

14. Friis-Moller N, Reiss P, Sabin CA (2007) Class of antiretroviral drugs and the risk of myocardial infarction. $\mathrm{N}$ Engl J Med 356: 1723-1735.

15. Day BJ and Lewis W (2004) Oxidative stress in NRTIinduced toxicity: evidence from clinical experience and experiments in vitro and in vivo. Cardiovasc Toxicol 4: 207216.

16. Lawler JM, Powers SK (1998) Oxidative stress, antioxidant status and, and the contracting diaphragm. Can J Appl Physiol 23: 23-55.

17. Dobmeyer TS, Findhammer S, Dobmeyer JM (1997) Ex vivo induction of apoptosis in lymphocytes is mediated by oxidative stress: role for lymphocyte loss in HIV infection. Free Radic Biol Med 22: 775-785.

18. Valcour V and Shiramizu B (2004) HIV-associated dementia, mitochondrial dysfunction, and oxidative stress. Mitochondrion 4: 119-129.

19. Walensky RP, Paltiel AD, Losina E (2006) The survival benefits of AIDS treatment in the United States. J Infect Dis 194: 11-19.

20. Morse CG, Kovacs JA (2006) Metabolic and skeletal complications of HIV infection: the price of success. JAMA 296: 844-854.

21. Martín JA, Sastre J, De la Asunción J, Pallardó FV, Vinña J (2001) Hepatic $\gamma$-cystathionase deficiency in patients with AIDS, JAMA 285: 1444-1445.

22. Hulgan T, Morrow R, D'Aquila T (2003) Oxidant stress is increased during treatment of human immunodeficiency virus infection. Clinical Infectious Diseases 37: 1711-1717.

23. Lizette G, Alicia T, Dayme H, Beatriz V R, Daniel P, Rolando T, Virginia C, Jorge P Altered oxidative stress indexes related to disease progression marker in human immunodeficiency virus infected patients with antiretroviral therapy. Biomedicine \& Pharmacotherapy. In Press.

24. Brinkman K, Smeitink JA, Romijn JA, Reiss P (1999) Mitochondrial toxicity induced by nucleoside-analogue reverse-transcriptase inhibitors is a key factor in the pathogenesis of antiretroviral-therapy-related lipodystrophy. Lancet 354: 1112-1115.

25. Montine KS, Quinn JF, Zhang J (2004) Isoprostanes and related products of lipid peroxidation in neurodegenerative diseases. Chem Phys Lipids 128: 117-124.

26. Shishehbor MH, Zhang R, Medina H, (2006) Systemic elevations of free radical oxidation products of arachidonic acid are associated with angiographic evidence of coronary artery disease. Free Radic Biol Med 41: 1678-1683.

27. Beers RF and Seizer IW (1952) A spectrophotometric method for measuring breakdown of hydrogen peroxide by catalase. Journal of Biological Chemistry 195: 133.

28. Beuge JA, Aust SD (1978) The thiobarbituri acid assay. Methods Enzymol 52: 306

29. Soon YY and Tan BKH (2002) Evaluation of the hypoglycemic and antioxidant activities of Morinda officinalis in streptozocin-induced diabetic rats. Singapore Medical Journal 43: 077-085.

30. Ebuehi OAT, Ajuluchukwu AE, Afolabi OT, Ebuehi OM, Akinwande AI (2009) Catalase activity, lipid peroxidation, Cholesterol and Triglyceride levels in Alloxan induced Diabetes Mellitus in Female and Male rats. Nig Q. J Hosp Med 19: 15-19. 
31. May ME and Spagnuolo PJ (1987) Evidence for activation of a respiratory burst in the interaction of human neutrophils; Free Radials and Anti-Oxidants 217. Indian Journal of Tuberculosis with Mycobacterium Tuberculosis. Infect Immun 55: 2304-2307.

32. Kuo HP, Ho TC, Wang CH, Yu CT, Lin HC (1996) Increased production of hydrogen peroxide and expression of $\mathrm{CD} 11 \mathrm{~b} / \mathrm{CD} 18$ on alveolar macrophages in patients with active pulmonary tuberculosis. Tuber Lung Dis 77: 468-475.

33. Jack CI, Jackson MJ, Hind CR (1994) Circulating markers of free radical activity in patients with pulmonary tuberculosis. Tuber Lung Dis 75: 132-137.

34. Zwart LL, Meerman JHN, Commandeur JNM, Vermeulen NPE (1999) Biomarkers of free radical damage applications in experimental animals and in humans. Free Radic Biol Med 26: 202.

35. Grimble RF (1994) Malnutrition and the immune response. Impact of nutrients on cytokine biology in infection. Trans $\mathrm{R}$ Soc Trop Med Hyg 88: 615-619.

36. Israël N, Gougerot-Pocidalo MA (1997) Oxidative stress in human immunodeficiency virus infection.Cellular and molecular life sciences. CMLS 53: 864-870.

37. Donnan SK (1950) The thiobarbituric acid applied to tissues from rats treated in various ways. J. Biol. Chem 182:v415419.
38. Delmas-Beauvieux MC, Peuchant E, Couchouron A, Constans J, Sergeant C, Simonoff M (1996) The enzymatic antioxidant system in blood and glutathione status in human immunodeficiency virus (HIV)-infected patients: effects of supplementation with selenium or beta-carotene. Am J Clin Nutr 64: 101-107.

39. Hemilia H, Kaprio J, Pietinen P, Albanes D, Heinonen OP (1994) Vitamin C and other compounds in vitamin C rich food in relation to risk of tuberculosis in male smokers. Am J Epidemiol 150: 632-641.

40. Adetifa IM, Temiye EO, Akinsulie AO, Ezeaka VC, Iroha EO (2006) Haematological Abnormalities Associated with Paediatric HIV/AIDS in Lagos. Annals of Tropical Paediatrics 26: 121-125.

\section{Corresponding author}

Awodele Olufunsho, MPH, PhD, FWPC Pharm

Address: Department of Pharmacology

College of Medicine

University of Lagos

PMB12003

Lagos, Nigeria

Telephone: +234-8023624044

Email: awodeleo@yahoo.com

Conflict of interests: No conflict of interests is declared. 